\title{
DYNAMIC REFORMING OF A QUASI PAY-AS-YOU-GO SOCIAL SECURITY SYSTEM WITHIN A DISCRETE STOCHASTIC MULTIDIMENSIONAL FRAMEWORK USING OPTIMAL CONTROL METHODS
}

Abstract. In many western economies, the phenomenon of ageing population implies that the large Pay-As-You-Go (PAYGO) social security system will run into several severe financial difficulties. In that direction, this paper constructs a discrete-time stochastic model for a quasi PAYGO social security system to allow the potential accumulation of a special (contingency) fund, which can oscillate so as to absorb fluctuations in the various system parameters involved. The basic difference equation is analytically designed including several control variables (i.e. different investment strategies, contribution rates, ages of eligibility for normal retirement and levels of pension benefits). The theoretical model is solved using standard linearization and stochastic optimization techniques resulting in analytic formulae for the control variables. These solutions are actually feedback mechanisms of the past fund values. Finally, we present a practical application for the projected population of Greece for the years 2007-2030 deriving a smooth solution for the development of the controls.

1. Introduction. Most of the E.U. economies experience the demographic phenomenon called the "ageing population" due to higher life expectancy and low fertility rates. Since most of these economies run several, large-scale social security pension plans financed by PAYGO systems, this may trigger increased taxation or contribution of workers or reducing benefits to pensioners. The potential significance of the problem is illustrated by the aged dependency ratio, i.e. the number of people at the working-age

2000 Mathematics Subject Classification: 91B30, 91B62, 93E20.

Key words and phrases: Pay-As-You-Go, social insurance, linearization techniques, stochastic optimal control, Hamiltonian matrix. 
over the number of elderly people, those aged 65 years and older,

(\# working-age)/(\# elderly).

Around 2010, the post-war generation, called the "baby boom" generation, will start retiring. This cohort of lives is numerous in the majority of the western developed countries. Greece is also going to experience one of the worst shifts in the dependency ratio which, according to the National Statistical Service of the country, is expected to fall to 2.65 in 2030 and drop below the critical value of 2.0 in 2050 (see Tables 1,2).

Table 1. Greek population, projections, 2007-2030

\begin{tabular}{|c|c|c|c|c|c|c|}
\hline & 2007 & 2010 & 2015 & 2020 & 2025 & 2030 \\
\hline & \multicolumn{7}{|c|}{ Population } \\
\hline $15-64$ & 7462.5 & 7480.8 & 7387.8 & 7271.1 & 7123.3 & 6928.2 \\
\hline $65+$ & 1994.5 & 2078.9 & 2195.0 & 2303.7 & 2446.2 & 2610.7 \\
\hline & \multicolumn{7}{|c|}{ Aged dependency ratio } \\
\hline & 3.74 & 3.60 & 3.36 & 3.16 & 2.91 & 2.65 \\
\hline
\end{tabular}

Table 2. European GDP and population, projections, 2000-2050 (\% per annum and ratios)

\begin{tabular}{|l|c|r|r|c|c|c|}
\hline & Real & \multicolumn{3}{|c|}{ Population } & \multicolumn{2}{c|}{ Aged dependency ratio } \\
\hline & GDP & Total & $15-64$ & $65+$ & 2000 & 2050 \\
\hline Denmark & 1.5 & 0.04 & -0.11 & 0.81 & 4.5 & 2.8 \\
\hline Germany & 1.4 & -0.17 & -0.47 & 0.93 & 4.2 & 2.0 \\
\hline Greece & 2.0 & -0.06 & -0.40 & 1.09 & 3.8 & 1.9 \\
\hline Spain & 1.8 & -0.23 & -0.67 & 1.13 & 4.0 & 1.7 \\
\hline France & 1.7 & 0.10 & -0.14 & 1.14 & 4.2 & 2.2 \\
\hline Ireland & 2.6 & 0.47 & 0.23 & 2.04 & 5.9 & 2.5 \\
\hline Italy & 1.4 & -0.36 & -0.79 & 0.90 & 3.7 & 1.6 \\
\hline Austria & 1.6 & -0.13 & -0.49 & 1.15 & 4.3 & 1.9 \\
\hline Portugal & 1.9 & 0.17 & -0.15 & 1.33 & 4.3 & 2.2 \\
\hline UK & 1.7 & 0.08 & -0.11 & 1.01 & 4.2 & 2.4 \\
\hline
\end{tabular}

Economic Policy Committee (2001), Table 3.4, p. 21 and Annex 7, pp. $109-110$

In view of the severe demographic forecasts, it is hardly surprising that reforms of the social security pension system have been at the front line of the policy debate. This debate focuses on (at least) two main issues. First, there are several questions about how the PAYGO financing system 
can be reformed absorbing effectively the demographic severity. Secondly, there are concerns about the future generations. Since the intergenerational solidarity is defined as the willingness of both young and old generations to participate in a common pool, sharing actual experience, including any losses emerging (see [7], [19] and [21] for further discussion), a potential change of the financing method should not generate double cost for a certain cohort of lives and an analogous deficit in the national budget till the whole system returns to a new equilibrium under a new financing method.

In its traditional form, the PAYGO pension system requires no accumulation of funds. However, in practice, there exists a small fund, but only for liquidity purposes. According to this method, the output of today's workforce is partially transferred to today's retirees. The equation which represents this transition is the following:

$$
b P=c s A
$$

where $b$ is the level of average pension and $P$ the number of eligible pensioners. Consumption on pensions, $b P$, is financed by an appropriate proportional contribution $c$ (percentage of the total salaries). Typically, there is an individual wage ceiling above which no contribution is collected, and normally a maximum pension is associated with it. If $A$ is the number of workers who participate in the scheme (not necessarily all the working-age population) and $s$ is the average salary, then $\operatorname{cs} A$ is the total revenue collected. This simple model shifts immediately any balance perturbation onto beneficiaries or/and contributors.

From the international demographic trends it is clear that the public pension systems of all countries operating under the PAYGO model will be faced with rising costs over the next few years (see also [20]). For instance, equation (1.1) demonstrates that, to maintain balance under a constant amount of a pension benefit, $c$ will have to increase if the decline in fertility rates leads to a decrease in $A$ and at the same time a decrease in mortality rates leads to an increase in $P$.

In this paper, one such fundamental reform is examined, and with that in mind a special purpose (contingency) fund for investment benefits is introduced buffering any kind of fluctuations in mortality, fertility rates (see [17]) or other worsening random events. This idea was first introduced by the authors of [9], who have constructed a PAYGO financing system with a contingency fund and they have controlled over time the two major variables of the system: the contribution rate and the age of normal retirement. Now, this idea is further enriched by the introduction of an appropriate balanced and active investment strategy. Additionally, further new variables are established for the management of the system. Hence, a comprehensive and convenient multi-dimensional model is introduced with several control vari- 
ables which also provide the opportunity of interaction among the different social security pension plans involved in the social system of each country. These variables are to be controlled through a smooth path over time. The smoothness of the path is determined by a functional which weighs changes in the variables involved. The weights are key parameters which reflect the expectations of all participants in the pension system as well as the underlying demographic trends.

Finally, the contingency fund returns to zero when the fluctuations disappear, leaving the system at a new equilibrium point regarding the major control variables. The specific fund can take positive or negative values. In the first (positive) case, there is a surplus that can be invested, while in the second (negative) case, there is a deficit which can be covered by borrowing. This concept of contingency fund improves the intergenerational equity by smoothing the rates of return produced for each cohort of lives.

The paper is organized as follows: Section 2 describes the general stochastic control model and offers the necessary notation; it also presents the linearization technique and concludes with the final difference equation. Section 3 describes the properties of the solution. Section 4 provides a detailed study of the solution of the model in the general case of $m$ social security pension plans. An application to the Greek population is described in Section 5. A summary and conclusions appear in Section 6.

2. The discrete-time framework model. This section proceeds with the presentation of the proposed model, translating the entire discussion and motivation of the previous section into mathematical equations. Firstly, the necessary notation is defined keeping in mind the discrete framework of our analysis. Throughout, $i=1, \ldots, m$.

$m$ : Number of different social security pension plans.

$C F_{i, n}$ : Contingency (reserve) fund at time $n \in \mathbb{N}$ (at the end of the $n$th period) for the $i$ th pension plan.

$r_{i, n}^{k}$ : Rate of return from a portfolio of $k$ different investments, $k=1, \ldots, d$, such as cash, bonds, shares etc., for the $(n+1)$ th period, i.e. in the time interval $[n, n+1)$, for the $i$ th pension plan. We assume that $r_{i, n}^{k}$ are stochastic variables.

$w_{i, n}^{k}$ : Proportions (weights) invested in $k$ different investments, $k=1, \ldots, d$, such as cash, bonds, shares, at time $n \in \mathbb{N}$ (constant during the whole $(n+1)$ th period) for the $i$ th pension plan. Obviously, $\sum_{k=1}^{d} w_{i, n}^{k}=1$, or equivalently, $w_{i, n}^{d}=1-\sum_{k=1}^{d-1} w_{i, n}^{k}$.

$c_{i, n}$ : Contribution rate at time $n \in \mathbb{N}$ (constant during the whole $(n+1)$ th period) for the $i$ th pension plan. 
$b_{i, n}$ : Average pension benefit paid to the pensioners due to normal retirement at time $n \in \mathbb{N}$ (or during the $(n+1)$ th period).

$a_{i, n}$ : Age of eligibility for normal retirement at time $n \in \mathbb{N}$ (or during the $(n+1)$ th period) for the $i$ th pension plan.

$s_{i, n}$ : Average salary received by the workers at time $n \in \mathbb{N}$ (or during the $(n+1)$ th period) for the $i$ th pension plan.

$A_{i ; n, a_{i, n}}$ : Total number of active members of the population at time $n \in \mathbb{N}$ (or during the $(n+1)$ th period) for the $i$ th pension plan, given that the age of eligibility for normal retirement is $a_{i, n}$.

$P_{i ; n, a_{i, n}}$ : Total number of pensioners due to normal retirement at time $n \in$ $\mathbb{N}$ (or during the $(n+1)$ th period) for the $i$ th pension plan, assuming that the age of eligibility equals $a_{i, n}$.

$\beta_{i j, n}$ : Interaction factor, the percentage of the contingency (reserve) fund transferred from the $i$ th to $j$ th pension plan at time $n \in \mathbb{N}$ (or during the $(n+1)$ th period) $, i, j=1, \ldots, m$. We have $\sum_{j=1}^{m} \beta_{i j, n}=1$ for all $i=1, \ldots, m$.

$\varepsilon_{i j, n}$ : Also an interaction factor, the transition cost for transferring monetary units from the $i$ th to $j$ th pension plan at time $n \in \mathbb{N}$ (or during the $(n+1)$ th period). It is expressed as a percentage of the contingency (reserve) fund.

Definition 2.1. The accumulated contingency (reserve) fund for the entire social security system at time $n \in \mathbb{N}$ (or during the $(n+1)$ th period) is defined by

$$
C F_{n}=\sum_{i=1}^{m} C F_{i, n} .
$$

Trivially, if we demand

$$
C F_{n}=0 \quad \text { for any } n \in \mathbb{N}
$$

equation (2.1) corresponds exactly to the initial balanced equation (1.1).

Furthermore, the accumulated contingency fund is determined by the following difference equation for $i=1, \ldots, m$ :

$$
\begin{aligned}
C F_{i, n+1} & =\sum_{l=1}^{i-1} \beta_{l i, n}\left(1-\varepsilon_{l i, n}\right) C F_{l, n}\left\{\beta_{i i, n}\left(1-\varepsilon_{i i, n}\right)\right. \\
& \left.+I_{C F_{i, n}>0}\left(\sum_{k=1}^{d} w_{i, n}^{k} r_{i, n}^{k}\right)\right\} C F_{i, n} \\
& +\sum_{l=i+1}^{m} \beta_{l i, n}\left(1-\varepsilon_{l i, n}\right) C F_{l, n}+c_{i, n} s_{i, n} A_{i ; n, a_{i, n}}-b_{i, n} P_{i ; n, a_{i, n}} .
\end{aligned}
$$


Thus, (2.3) determines a dynamical system, where

$$
I_{x>0}(Y)= \begin{cases}Y & \text { when } x>0 \\ 0 & \text { otherwise }\end{cases}
$$

$\left\{C F_{i, n}\right\}_{n \in \mathbb{N}}$ is the sequence of state variables, $\left\{w_{i, n}^{k}\right\}_{n \in \mathbb{N}}$ for $k=1, \ldots, d$, $\left\{c_{i, n}\right\}_{n \in \mathbb{N}},\left\{b_{i, n}\right\}_{n \in \mathbb{N}},\left\{a_{i, n}\right\}_{n \in \mathbb{N}}$ are the deterministic control variables, and $\left\{r_{i, n}^{k}\right\}_{n \in \mathbb{N}}$ for $k=1, \ldots, d,\left\{A_{i ; n, a_{i, n}}\right\}_{n \in \mathbb{N}},\left\{P_{i ; n, a_{i, n}}\right\}_{n \in \mathbb{N}},\left\{s_{n}\right\}_{n \in \mathbb{N}},\left\{\beta_{i j, n}\right\}_{n \in \mathbb{N}}$ and $\left\{\varepsilon_{i j, n}\right\}_{n \in \mathbb{N}}$ are the input variables for $i=1, \ldots, m$.

By using equation (2.3), the variables that restrict the development of the process are controlled by demanding the fulfillment of the minimization criterion (2.4) which produces a smooth path for the evolution of the control variables, i.e.

$$
\min _{\substack{w_{i, n}^{1}, \ldots, w_{i, n}^{d-1} \\
c_{i, n}, b_{i, n}, a_{i, n}}} \mathbb{E}\left\{\begin{array}{c}
\sum_{n=1}^{N}\left\{\sum_{k=1}^{d-1} \theta_{i, k}\left[100\left(w_{i, n}^{k}-\bar{w}_{i, n}^{k}\right)\right]^{2}\right. \\
+\theta_{i, d}\left[100\left(c_{i, n}-\bar{c}_{i, n}\right)\right]^{2} \\
\left.+\theta_{i, d+1}\left(b_{i, n}-\bar{b}_{i, n}\right)^{2}+\theta_{i, d+2}\left(a_{i, n}-\bar{a}_{i, n}\right)^{2}\right\} \\
+\left(1-\sum_{k=1}^{d+2} \theta_{i, k}\right)\left(C F_{i, N}-C \bar{F}_{i, N}\right)^{2}
\end{array}\right\},
$$

where

$\left\{\bar{w}_{i, n}^{k}\right\}_{n \in \mathbb{N}}$ : The sequence of standard values for the proportions invested in $k$ different investments, $k=1, \ldots, d-1$, such as bonds, cash, shares etc. for the $i$ th pension plan. They can be considered as the initial values or average values near to which the path of the future values of $\left\{\bar{w}_{i, n}^{k}\right\}_{n \in \mathbb{N}}, k=1, \ldots, d-1$, is placed using the smoothing process.

$\left\{\bar{c}_{i, n}\right\}_{n \in \mathbb{N}},\left\{\bar{a}_{i, n}\right\}_{n \in \mathbb{N}},\left\{\bar{b}_{i, n}\right\}_{n \in \mathbb{N}}$ : The sequences of standard values for the contribution rate, the age of retirement and the benefits of pensioners, respectively, for the $i$ th pension plan, with explanation similar to that for $\left\{\bar{w}_{i, n}^{k}\right\}_{n \in \mathbb{N}}, k=1, \ldots, d-1$.

$C \bar{F}_{i, N}$ : A desirable final value for the contingency (reserve) fund, obtained from this operation at the end of period $N$ for the $i$ th pension plan. Note the importance of expressions (2.1) and (2.2).

The weights $\theta_{i, j}$ for $i=1, \ldots, m, j=1, \ldots, d+2\left(\right.$ and $\left.\sum_{j=1}^{4} \theta_{i, j}=1\right)$ measure the impact of changes in the control variables $w_{i, n}^{1}, \ldots, w_{i, n}^{d-1}, c_{i, n}$, $b_{i, n}, a_{i, n}$ and $C F_{i, n}$, for $i=1, \ldots, m$. The parameters would be obtained after research and negotiations with all parties involved in the public pension system (i.e. authorities, employees, employers etc.). Additionally, some coefficients are multiplied by 100 , see (2.4), in order to deal with the mea- 
surement unit problem. Note that $b_{i, n}$ and $a_{i, n}$ are greater than 1 (near 60 and 65 , respectively). form:

For the sequences $\left\{A_{i ; n, a_{i, n}}\right\}_{n \in \mathbb{N}}$ and $\left\{P_{i ; n, a_{i, n}}\right\}_{n \in \mathbb{N}}$, we assume a quadratic

$$
\begin{aligned}
& A_{i ; n, a_{i, n}}=\lambda_{i, 1} n+\lambda_{i, 2} a_{i, n}+\lambda_{i, 3} n^{2}+\lambda_{i, 4} a_{i, n}^{2}+\lambda_{i, 5} n a_{i, n}+\lambda_{i ; 6, n}, \\
& P_{i ; n, a_{i, n}}=k_{i, 1} n+k_{1,2} a_{i, n}+k_{i, 3} n^{2}+k_{i, 4} a_{i, n}^{2}+k_{i, 5} n a_{i, n}+k_{i ; 6, n},
\end{aligned}
$$

where $k_{i, k}, \lambda_{i, k}, k=1, \ldots, 5$, are constant coefficients and $\lambda_{i ; 6, n}, k_{i ; 6, n}$ are stochastic variables. This last assumption for $\lambda_{i ; 6, n}, k_{i ; 6, n}$ incorporates a stochastic element into the fully quadratic projections of the number of active members and the number of pensioners.

Proposition 2.1. The nonlinear equation (2.3) can be rewritten in the vector linear form

$$
x_{i, n+1}=\mathbf{a}_{1} \mathbf{x}_{n}+\mathbf{b}_{i} \mathbf{u}_{i, n}+\mathbf{c}_{i} \mathbf{w}_{i, n}+\phi_{i} \quad \text { for } i=1, \ldots, m,
$$

by applying the standard linearization technique where

$$
\begin{gathered}
x_{i, n+1}=\Delta P_{i, n+1}, \\
\mathbf{a}_{i}=\left[\begin{array}{lll}
A_{1 i} & \cdots & A_{m i}
\end{array}\right] \in \mathbb{R}^{1 \times m} .
\end{gathered}
$$

Note that $\beta_{i j, n} \equiv \bar{\beta}_{i j, n}$ and $\varepsilon_{i j, n} \equiv \bar{\varepsilon}_{i j, n}$ are constant. The elements of $(2.7)$ are

$$
A_{j i}=\left\{\begin{array}{l}
\bar{\beta}_{j i, n}\left(1-\bar{\varepsilon}_{j i, n}\right) \quad \text { for } j \neq i, \\
\quad+I_{C F_{i, n}>0}\left(\sum_{k=1}^{d-1} \bar{w}_{i, n}^{k} \bar{r}_{i, n}^{k}+\left(1-\sum_{k=1}^{d-1} \bar{w}_{i, n}^{k}\right) \bar{r}_{i, n}^{d}\right) \\
\quad \text { for }
\end{array}\right.
$$
for $j=i$,

2.9) $\quad \mathbf{x}_{n}=\left[\Delta C F_{1, n} \cdots \Delta C F_{m, n}\right]^{\prime} \in \mathbb{R}^{m}$,

$$
\begin{array}{r}
\mathbf{b}_{i}=\left[I_{C F_{i, n}>0}\left(\bar{r}_{i, n}^{1}-\bar{r}_{i, n}^{d}\right) C \bar{F}_{i, n} \cdots I_{C F_{i, n}>0}\left(\bar{r}_{i, n}^{d-1}-\bar{r}_{i, n}^{d}\right) C \bar{F}_{i, n}\right. \\
\left.\gamma_{i} \bar{s}_{i, n}-\delta_{i} \eta_{i}\right] \in \mathbb{R}^{1 \times(d+2)},
\end{array}
$$

where

$$
\begin{aligned}
\eta_{i} & =\bar{c}_{i, n} \bar{s}_{i, n}\left[\lambda_{i, 2}+2 \lambda_{i, 4} \bar{a}_{i, n}+\lambda_{i, 5} n\right]-\bar{b}_{i, n}\left[k_{i, 2}+2 k_{i, 4} \bar{a}_{i, n}+k_{i, 5} n\right], \\
\gamma_{i} & =\lambda_{i, 1} n+\lambda_{i, 2} \bar{a}_{i, n}+\lambda_{i, 3} n^{2}+\lambda_{i, 4} \bar{a}_{i, n}^{2}+\lambda_{i, 5} n \bar{a}_{i, n}+\bar{\lambda}_{i ; 6, n},
\end{aligned}
$$

and

$$
\begin{aligned}
\delta_{i} & =k_{i, 1} n+k_{i, 2} \bar{a}_{i, n}+k_{i, 3} n^{2}+k_{i, 4} \bar{a}_{i, n}^{2}+k_{i, 5} n \bar{a}_{i, n}+\bar{k}_{i ; 6, n}, \\
\mathbf{u}_{i, n} & =\left[\begin{array}{lll}
\Delta w_{i, n}^{1} & \cdots & \Delta w_{i, n}^{d-1} \Delta c_{i, n} \Delta \beta_{i, n} \Delta a_{i, n}
\end{array}\right]^{\prime} \in \mathbb{R}^{d+2}, \\
\mathbf{c}_{i} & =\left[\begin{array}{lll}
c_{1 i} & \cdots & c_{d+3, i}
\end{array}\right] \in \mathbb{R}^{1 \times(d+3)},
\end{aligned}
$$


where

$$
\begin{aligned}
c_{j i} & = \begin{cases}\bar{w}_{i, n}^{j} C \bar{F}_{i, n} & \text { for } j=1, \ldots, d-1, \\
\left(1-\sum_{k=1}^{d-1} \bar{w}_{i, n}^{k}\right) C \bar{F}_{i, n} & \text { for } j=d, \\
\gamma_{i} \bar{c}_{i, n} & \text { for } j=d+1, \\
\bar{c}_{i, n} \bar{s}_{i, n} & \text { for } j=d+2, \\
-\bar{b}_{n} & \text { for } j=d+3,\end{cases} \\
\mathbf{w}_{i, n} & =\left[\begin{array}{lll}
\Delta r_{i, n}^{1} \cdots \Delta r_{i, n}^{d-1} \Delta r_{i, n}^{d} & \Delta s_{i, n} \Delta \lambda_{i, n} \Delta k_{i, n}
\end{array}\right]^{\prime} \in \mathbb{R}^{d+3}
\end{aligned}
$$

and

(2.16) $\phi_{i}=\bar{c}_{i, n} \bar{w}_{i, n}\left[\lambda_{i, 1}+2 \lambda_{i, 3} n+\lambda_{i, 5} \bar{a}_{i, n}\right]-\bar{b}_{i, n}\left[k_{i, 1}+2 k_{i, 3} n+k_{i, 5} \bar{a}_{i, n}\right] \in \mathbb{R}$.

Proof. By substituting (2.5) into equation (2.3), we obtain

$$
\begin{aligned}
C F_{i, n+1}= & \sum_{l=1}^{i-1} \beta_{l i, n}\left(1-\varepsilon_{l i, n}\right) C F_{l, n} \\
& +\left\{\beta_{i i, n}\left(1-\varepsilon_{i i, n}\right)+I_{C F_{i, n}>0}\left(\sum_{k=1}^{d} w_{i, n}^{k} r_{i, n}^{k}\right)\right\} C F_{i, n} \\
& +\sum_{l=i+1}^{m} \beta_{l i, n}\left(1-\varepsilon_{l i, n}\right) C F_{l, n} \\
& +c_{i, n} s_{i, n}\left(\lambda_{i, 1} n+\lambda_{i, 2} a_{i, n}+\lambda_{i, 3} n^{2}+\lambda_{i, 4} a_{i, n}^{2}+\lambda_{i, 5} n a_{i, n}+\lambda_{i ; 6, n}\right) \\
& -b_{i, n}\left(k_{i, 1} n+k_{i, 2} a_{i, n}+k_{i, 3} n^{2}+k_{i, 4} a_{i, n}^{2}+k_{i, 5} n a_{i, n}+k_{i ; 6, n}\right) .
\end{aligned}
$$

The above equation is difficult to solve as it has a nonlinear form. For this reason, we employ a standard linearization technique considering the $\Delta$ operator at the equilibrium point for the $i$ th pension plan, $i=1, \ldots, m$ (see $[22])$. Thus the nominal solution is

$$
\left(n, C \bar{F}_{i, n}, \bar{w}_{i, n}^{h}, \bar{r}_{i, n}^{k}, \bar{c}_{i, n}, \bar{b}_{i, n}, \bar{a}_{i, n}, \bar{s}_{i, n}, \bar{\lambda}_{i ; 6, n}, \bar{k}_{i ; 6, n}\right)
$$

for $h=1, \ldots, d-1$ and $k=1, \ldots, d$ and imperceptibly small changes for the parameters, i.e. $\Delta f_{i, n}=f_{i, n}-\bar{f}_{i, n}$ for every parameter of the nominal solution above. Now, recall that $r_{i, n}^{k}, s_{i, n}, \lambda_{i, n}$ and $k_{i, n}$ are stochastic variables, so the terms $\Delta r_{i, n}^{k}, \Delta w_{i, n}, \Delta \lambda_{i, n}$ and $\Delta k_{i, n}$ are also stochastic variables. Then, for the $i$ th pension plan, we obtain

$$
=\Delta\left\{\begin{array}{r}
\Delta C F_{i, n+1} \\
\sum_{l=1}^{i-1} \beta_{l i, n}\left(1-\varepsilon_{l i, n}\right) C F_{i, n}+\left\{\beta_{i i, n}\left(1-\varepsilon_{i i, n}\right)+I_{C F_{i, n}>0}\left(\sum_{k=1}^{d} w_{i, n}^{k} r_{i, n}^{k}\right)\right\} C F_{i, n} \\
+\sum_{l=i+1}^{m} \beta_{l i, n}\left(1-\varepsilon_{l i, n}\right) C F_{l, n}
\end{array}\right\}
$$




$$
\begin{aligned}
& +\Delta\left\{\begin{array}{r}
c_{i, n} s_{i, n}\left(\lambda_{i, 1} n+\lambda_{i, 2} a_{i, n}+\lambda_{i, 3} n^{2}+\lambda_{i, 4} a_{i, n}^{2}+\lambda_{i, 5} n a_{i, n}+\lambda_{i ; 6, n}\right) \\
-b_{i, n}\left(k_{i, 1} n+k_{i, 2} a_{i, n}+k_{i, 3} n^{2}+k_{i, 4} a_{i, n}^{2}+k_{i, 5} n a_{i, n}+k_{i ; 6, n}\right)
\end{array}\right\} \\
& =\sum_{l=1}^{i-1} \bar{\beta}_{l i, n}\left(1-\bar{\varepsilon}_{l, i, n}\right) \Delta C F_{l, n} \\
& +\left\{\bar{\beta}_{i i, n}\left(1-\bar{\varepsilon}_{i i, n}\right)+I_{C F_{i, n}>0}\left(\sum_{k=1}^{d-1} \bar{w}_{i, n_{0}}^{k} \bar{r}_{i, n_{0}}^{k}+\left(1-\sum_{k=1}^{d-1} \bar{w}_{i, n}^{k}\right) \bar{r}_{i, n}^{d}\right)\right\} \Delta C F_{i, n} \\
& +\sum_{l=l+1}^{m} \bar{\beta}_{l, i, n}\left(1-\bar{\varepsilon}_{l, i, n}\right) \Delta C F_{l, n} \\
& +I_{C F_{i, n}>0}\left\{C \bar{F}_{i, n}\left(\sum_{k=1}^{d-1}\left(\bar{r}_{i, n}^{k}-\bar{r}_{i, n}^{d}\right)\right) \Delta \bar{w}_{i, n}^{k}+C \bar{F}_{i, n} \bar{r}_{i, n}^{d} \Delta w_{i, n}^{d}\right\} \\
& +I_{C F_{i, n}>0}\left\{C \bar{F}_{i, n} \sum_{k=1}^{d-1} \bar{w}_{i, n}^{k} \Delta r_{i, n}^{k}+C \bar{F}_{i, n}\left(1-\sum_{k=1}^{d-1} \bar{w}_{i, n}^{k}\right) \Delta r_{i, n}^{d}\right\} \\
& +\gamma_{i} \bar{s}_{i, n} \Delta c_{i, n}+\gamma_{i} \bar{c}_{i, n} \Delta s_{i, n}-\delta_{i} \Delta b_{i, n}+\bar{c}_{i, n} \bar{s}_{i, n} \Delta \lambda_{i ; 6, n}-\bar{b}_{n} \Delta k_{i ; 6, n} \\
& +\left\{\bar{c}_{i, n} \bar{s}_{i, n}\left[\lambda_{i, 2}+2 \lambda_{i, 4} \bar{a}_{i, n}+\lambda_{i, 5} n\right]-\bar{b}_{i, n}\left[k_{i, 2}+2 k_{i, 4} \bar{a}_{i, n}+k_{i, 5} n\right]\right\} \Delta a_{i, n} \\
& +\left\{\bar{c}_{i, n} \bar{s}_{i, n}\left[\lambda_{i, 1}+2 \lambda_{i, 3} n+\lambda_{i, 5} \bar{a}_{i, n}\right]-\bar{b}_{i, n}\left[k_{i, 1}+2 k_{i, 3} n+k_{i, 5} \bar{a}_{i, n}\right]\right\} .
\end{aligned}
$$

It is obvious that each of the $m$ pension plans generates its own system of equations, as shown by the above vector equation (2.6). However, these systems cannot be solved independently because of the existence of interaction factors.

Definition 2.2. We define three matrices, $\mathbf{A}, \mathbf{B}$ and $\mathbf{C}$ :

$$
\mathbf{A} \triangleq\left[\mathbf{a}_{1}^{\prime} \cdots \mathbf{a}_{m}^{\prime}\right]^{\prime} \in \mathbb{R}^{m \times m},
$$

where $\mathbf{a}_{i} \in \mathbb{R}^{1 \times m}, i=1, \ldots, m$, is given by (2.7) and (2.8);

$$
\mathbf{B} \triangleq \operatorname{diag}\left\{\mathbf{b}_{1}, \ldots, \mathbf{b}_{m}\right\} \in \mathbb{R}^{m \times m},
$$

where $\mathbf{b}_{i} \in \mathbb{R}^{1 \times(d+2)}, i=1, \ldots, m$, is given by (2.10) and (2.12);

$$
\mathbf{C} \triangleq \operatorname{diag}\left\{\mathbf{c}_{1}, \ldots, \mathbf{c}_{m}\right\} \in \mathbb{R}^{m \times m},
$$

where $\mathbf{c}_{i} \in \mathbb{R}^{1 \times(d+3)}, i=1, \ldots, m$, is given by (2.13) and (2.14). Finally,

$$
\varphi \triangleq\left[\begin{array}{lll}
\varphi_{1} & \ldots & \varphi_{m}
\end{array}\right] \in \mathbb{R}^{m} \text {. }
$$

Combining equations (2.6) for all $i=1, \ldots, m$ leads to the construction of the following difference matrix equation that describes the accumulated profit or loss and the interactions within the portfolio of pension plans:

$$
\mathbf{x}_{n+1}=\mathbf{A} \mathbf{x}_{n}+\mathbf{B} \mathbf{u}_{n}+\mathbf{C} \mathbf{w}_{n}+\varphi,
$$

where the state vector $\mathbf{x}_{n} \in \mathbb{R}^{m}$ is given by (2.9). However, taking into consideration (2.12), the control vector $\mathbf{u}_{n} \in \mathbb{R}^{m}$ obtains the following form: 


$$
\mathbf{u}_{n}=\left[\begin{array}{lll}
\mathbf{u}_{1, n} & \cdots & \mathbf{u}_{m, n}
\end{array}\right]^{\prime} \in \mathbb{R}^{m} .
$$

Furthermore, the input vector $\mathbf{w}_{n} \in \mathbb{R}^{d+3}$ is expressed by (2.19).

Keeping in mind that $\mathbf{w}_{n}$ is the only stochastic vector, because it contains all the stochastic elements, we substitute the expressions of optimal control from (2.22) into the objective function (2.4). So, we obtain

$$
\min _{\mathbf{u}_{n}} \mathbb{E}\left\{\sum_{n=1}^{N} \mathbf{u}_{n}^{\prime} \cdot \mathbf{R} \cdot \mathbf{u}_{n}+\mathbf{x}_{N}^{\prime} \mathbf{Q} \mathbf{x}_{N}\right\},
$$

where

$$
\mathbf{R} \triangleq \operatorname{diag}\left\{\boldsymbol{\Lambda}_{1}, \ldots, \boldsymbol{\Lambda}_{m}\right\}, \quad \boldsymbol{\Lambda}_{i}=\operatorname{diag}\left\{l_{i, 1}, \ldots, l_{i, d+2}\right\}
$$

and

$$
\mathbf{Q} \triangleq \operatorname{diag}\left\{1-\sum_{k=1}^{d+2} \theta_{1, k}, \ldots, 1-\sum_{k=1}^{d+2} \theta_{m, k}\right\} \in \mathbb{R}^{m \times m}
$$

where

$$
l_{i, k}=100^{2} \theta_{i, k} \quad \text { for } k=1, \ldots, d, \quad l_{i, d+1}=\theta_{i, d+1}, \quad l_{i, d+2}=\theta_{i, d+2} .
$$

i.e. $\mathbf{R}$ is a positive semidefinite, diagonal matrix and $\mathbf{Q}$ is also a positive definite symmetric matrix, as required by the assumptions of [11], [6], [15] and [3] for the solution of the relevant optimization (minimization) problem. That is described extensively in the next sections.

3. Properties and the solution of the model. In this section, a functional optimization (minimization) procedure within a stochastic framework is extensively discussed for the solution of the standard matrix difference equation (2.21).

Consider the linear difference equation

$$
\mathbf{x}_{n+1}=\mathbf{A} \mathbf{x}_{n}+\mathbf{B} \mathbf{u}_{n}+\mathbf{C w}_{n}+\varphi
$$

where $\mathbf{x}_{n} \in \mathbb{R}^{m}$ is the state variable, $\mathbf{u}_{n} \in \mathbb{R}^{m}$ is the control variable and $\mathbf{w}_{n} \in \mathbb{R}^{m}$ is the input variable. Then $\mathbf{w}_{n}$ is a random vector with zero mean, finite covariance $E\left(\mathbf{w}_{n} \mathbf{w}_{n}^{\prime}\right)=G$ and finite second moment while it is independent of $\mathbf{x}_{n-1}$ and $\mathbf{u}_{n}$. Additionally, $\mathbf{A}, \mathbf{B}, \mathbf{C} \in \mathbb{R}^{m \times m}$ are constant matrices and $\varphi$ is a constant vector.

We search for the optimal control $\mathbf{u}_{n}$ (i.e. determine $\mathbf{u}_{1, n}, \ldots, \mathbf{u}_{m, n}$ ) that minimizes the expression

$$
\mathbb{E}\left\{\sum_{n=1}^{N} \mathbf{u}_{n}^{\prime} \cdot \mathbf{R} \cdot \mathbf{u}_{n}+\mathbf{x}_{N}^{\prime} \mathbf{Q} \mathbf{x}_{N}\right\},
$$

where $\mathbf{R}$ and $\mathbf{Q}$ are positive semidefinite and positive definite symmetric matrices, respectively. 
THEOREM 3.1. If the system is stable (i.e., all the characteristic roots of $\mathbf{A}+\mathbf{B M}$ are smaller than 1 in absolute value), then the solution ultimately converges and is given by

$$
\mathbf{u}_{n}=\mathbf{M} \mathbf{x}_{n-1}+\zeta
$$

where

$$
\begin{aligned}
\mathbf{M} & =-\left(\mathbf{B}^{\prime} \mathbf{H B}+\mathbf{R}\right)^{-1} \mathbf{B}^{\prime} \mathbf{H A}, \\
\mathbf{H} & =\mathbf{A}^{\prime}\left[\mathbf{H}-\mathbf{H B}\left(\mathbf{B}^{\prime} \mathbf{H B}+\mathbf{R}\right)^{-1} \mathbf{B}^{\prime} \mathbf{H}\right] \mathbf{A}+\mathbf{Q}, \\
\zeta & =-\left(\mathbf{B}^{\prime} \mathbf{H B}+\mathbf{R}\right)^{-1}\left(\mathbf{B}^{\prime} \mathbf{H} \varphi\right) .
\end{aligned}
$$

Proof. See [11] and [3] for more details.

The analytic solution of the above linear quadratic control problem (2.21) relies on solving equation (3.3). In that direction there exist several numerically stable algorithms for the solution of the algebraic matrix Riccati equation, [16]. In this paper, a rather straightforward method is used for determining the Hamiltonian matrix $H,[13]$, [1], [2], and [10], given by the following expression:

$$
H=\left[\begin{array}{cc}
\mathbf{A}+\mathbf{B R}^{-1} \mathbf{B}^{\prime}\left(\mathbf{A}^{\prime}\right)^{-1} \mathbf{Q} & -\mathbf{B R}^{-1} \mathbf{B}^{\prime}\left(\mathbf{A}^{\prime}\right)^{-1} \\
-\left(\mathbf{A}^{\prime}\right)^{-1} \mathbf{Q} & \left(\mathbf{A}^{\prime}\right)^{-1}
\end{array}\right]
$$

where it is assumed that $\mathbf{A}^{-1}$ exists. Denote by

$$
\left[\begin{array}{ll}
\mathbf{V}_{1}^{\prime} & \mathbf{V}_{2}^{\prime}
\end{array}\right]^{\prime}
$$

the matrix of $2 m$ eigenvectors corresponding to the stable and unstable eigenvalues of the Hamiltonian matrix $H$. Analytically, $\mathbf{V}_{1}$ and $\mathbf{V}_{2}$ are formed by the $m$ eigenvectors corresponding to the $m$ stable $(|\lambda|<1)$ and $m$ unstable eigenvalues of $H$ respectively. Note that of the $2 m$ eigenvalues of $H$, only $m$ are stable (i.e. within the unit circle). Furthermore, since an optimal control system is considered, the solution of the algebraic matrix Riccati equation is provided by the expression

$$
\mathbf{H}=\mathbf{V}_{2} \mathbf{V}_{1}^{-1} \text {. }
$$

COROLlary 3.2. The optimal choice of the control vector (3.1)

$$
\begin{gathered}
\mathbf{u}_{n}=\left[\begin{array}{lll}
\mathbf{u}_{1, n} & \cdots & \mathbf{u}_{m, n}
\end{array}\right]^{\prime} \in \mathbb{R}^{m}, \\
\mathbf{u}_{i, n}=\sum_{j=1}^{m} \mathbf{M}_{i j}\left(\mathbf{x}_{j, n-1}+\left(\mathbf{A}^{-1} \varphi\right)_{j}\right) \quad \text { for every } i=1, \ldots, m,
\end{gathered}
$$

where

$$
\begin{gathered}
\mathbf{M}_{i j} \in \mathbb{R}^{d+2}, \\
\mathbf{u}_{i, n}=\left[\begin{array}{lll}
\Delta m_{i, n}^{1} & \cdots & \Delta m_{i, n}^{d-1} \Delta c_{i, n} \Delta b_{i, n} \Delta a_{i, n}
\end{array}\right]^{T} \in \mathbb{R}^{d+2}
\end{gathered}
$$

for the $d+2$ controls. 
Proof. The expression (3.2) is transformed to

$$
\mathbf{M}=-\left(\mathbf{B}^{\prime} \mathbf{V}_{2} \mathbf{V}_{1}^{-1} \mathbf{B}+\mathbf{R}\right)^{-1} \mathbf{B}^{\prime} \mathbf{V}_{2} \mathbf{V}_{1}^{-1} \mathbf{A}
$$

and the analytic expression for the control vector is

$$
\mathbf{u}_{n}=-\left(\mathbf{B}^{\prime} \mathbf{V}_{2} \mathbf{V}_{1}^{-1} \mathbf{B}+\mathbf{R}\right)^{-1} \mathbf{B}^{\prime} \mathbf{V}_{2} \mathbf{V}_{1}^{-1} \mathbf{A} \mathbf{x}_{n-1}+\zeta .
$$

Combining also equations (3.2) and (3.4), we obtain

$$
\zeta=\mathbf{M A}^{-1} \in \mathbb{R}^{m} .
$$

Hence, the optimal choice for the control vector is determined by equation (3.13) (see also next section) or equivalently,

$$
\mathbf{u}_{n}=\left[\begin{array}{c}
\mathbf{u}_{1, n} \\
\vdots \\
\mathbf{u}_{m, n}
\end{array}\right]=\left[\begin{array}{ccc}
\mathbf{M}_{11} & \cdots & \mathbf{M}_{1 m} \\
\vdots & \ddots & \vdots \\
\mathbf{M}_{m 1} & \cdots & \mathbf{M}_{m m}
\end{array}\right]\left[\begin{array}{c}
x_{1, n-1}+\left(\mathbf{A}^{-1} \varphi\right)_{1} \\
\vdots \\
x_{m, n-1}+\left(\mathbf{A}^{-1} \varphi\right)_{m}
\end{array}\right] \text {. . }
$$

4. The analytic solution for $m$ social security pension plans. To further illustrate the ideas presented in the pervious sections, let us describe a complex model with $m$ social security pension plans.

Consider the matrices $\mathbf{A} \triangleq\left[a_{k l}\right]_{1 \leq k, l \leq m} \in \mathbb{R}^{m \times m}$ and $\mathbf{A}^{-1} \triangleq\left[\alpha_{k l}\right]_{1 \leq k, l \leq m}$ $\in \mathbb{R}^{m \times m}$.

Lemma 4.1. The Hamiltonian matrix is given by (3.5) and

$$
\begin{aligned}
& \mathbf{A}+\mathbf{B R}^{-1} \mathbf{B}^{\prime}\left(\mathbf{A}^{\prime}\right)^{-1} \mathbf{Q} \\
& =\left[\begin{array}{ccc}
a_{11}+d_{1} \alpha_{11} \mathbf{B}_{1} \boldsymbol{\Lambda}_{1}^{-1} \mathbf{B}_{1}^{\prime} & \cdots & a_{1 m}+d_{m} \alpha_{m 1} \mathbf{B}_{1} \boldsymbol{\Lambda}_{1}^{-1} \mathbf{B}_{1}^{\prime} \\
\vdots & \ddots & \vdots \\
a_{m 1}+d_{1} \alpha_{1 m} \mathbf{B}_{m} \boldsymbol{\Lambda}_{m}^{-1} \mathbf{B}_{m}^{\prime} & \cdots & a_{m m}+d_{m} \alpha_{m m} \mathbf{B}_{m} \boldsymbol{\Lambda}_{m}^{-1} \mathbf{B}_{m}^{\prime}
\end{array}\right] \in \mathbb{R}^{m \times m}
\end{aligned}
$$

where $d_{i}=1-\sum_{k=1}^{d+2} \theta_{i, k} / \operatorname{det}(\mathbf{A})$ for $i=1, \ldots, m$. Additionally,

$$
-\mathbf{B R}^{-1} \mathbf{B}^{\prime}\left(\mathbf{A}^{\prime}\right)^{-1}=\left[\begin{array}{ccc}
\alpha_{11} \mathbf{B}_{1} \boldsymbol{\Lambda}_{1}^{-1} \mathbf{B}_{1}^{\prime} & \cdots & \alpha_{m 1} \mathbf{B}_{1} \boldsymbol{\Lambda}_{1}^{-1} \mathbf{B}_{1}^{\prime} \\
\vdots & \ddots & \vdots \\
\alpha_{1 m} \mathbf{B}_{m} \boldsymbol{\Lambda}_{m}^{-1} \mathbf{B}_{m}^{\prime} & \cdots & \alpha_{m m} \mathbf{B}_{m} \boldsymbol{\Lambda}_{m}^{-1} \mathbf{B}_{m}^{\prime}
\end{array}\right] \in \mathbb{R}^{m \times m}
$$

Finally,

$$
H=\left[\begin{array}{cc}
\mathbf{A}+\mathbf{B R}^{-1} \mathbf{B}^{\prime}\left(\mathbf{A}^{\prime}\right)^{-1} \mathbf{Q} & -\mathbf{B} \mathbf{R}^{-1} \mathbf{B}^{\prime}\left(\mathbf{A}^{\prime}\right)^{-1} \\
-\left(\mathbf{A}^{\prime}\right)^{-1} \mathbf{Q} & \left(\mathbf{A}^{\prime}\right)^{-1}
\end{array}\right]
$$




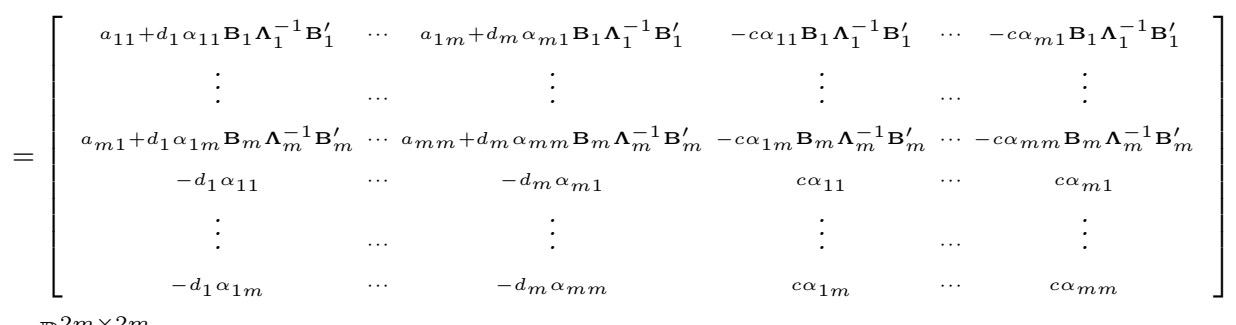

$\in \mathbb{R}^{2 m \times 2 m}$,

where $c=1 / \operatorname{det}(\mathbf{A})$.

Proof. The proof is straightforward.

The matrices $\mathbf{V}_{1}^{-1}$ and $\mathbf{V}_{2}$ are defined as follows:

$$
\mathbf{V}_{1}^{-1}=\left[v_{k j}\right]_{1 \leq k, l \leq m} \in \mathbb{R}^{m \times m}, \quad \mathbf{V}_{2}=\left[u_{k l}\right]_{1 \leq k, l \leq m} \in \mathbb{R}^{m \times m} .
$$

Now, to calculate the respective coordinates, $\mathbf{M}_{11}, \mathbf{M}_{12}, \ldots, \mathbf{M}_{m m}$ (see expression (3.10)), the inverse matrix of $\mathbf{B}^{\prime} \mathbf{V}_{2} \mathbf{V}_{1}^{-1} \mathbf{B}+\mathbf{R}$ should be determined.

Proposition 4.2. The inverse matrix of $\mathbf{B}^{\prime} \mathbf{V}_{2} \mathbf{V}_{1}^{-1} \mathbf{B}+\mathbf{R}$ is given by $\left(\mathbf{B}^{\prime} \mathbf{V}_{2} \mathbf{V}_{1}^{-1} \mathbf{B}+\mathbf{R}\right)^{-1} \triangleq\left[\widetilde{\mathbf{B}}_{k l}\right]_{1 \leq k, l \leq m}=$

$\operatorname{diag}\left\{\boldsymbol{\Lambda}_{1}, \ldots, \boldsymbol{\Lambda}_{m}\right\}+\left[\begin{array}{ccc}u_{11} \mathbf{B}_{1}^{\prime} & \cdots & u_{1 m} \mathbf{B}_{1}^{\prime} \\ \vdots & \vdots & \vdots \\ u_{m 1} \mathbf{B}_{m}^{\prime} & \cdots & u_{m m} \mathbf{B}_{m}^{\prime}\end{array}\right]\left[\begin{array}{ccc}v_{11} \mathbf{B}_{1}^{\prime} & \cdots & v_{1 m} \mathbf{B}_{m}^{\prime} \\ \vdots & \vdots & \vdots \\ v_{m 1} \mathbf{B}_{1}^{\prime} & \cdots & v_{m m} \mathbf{B}_{m}^{\prime}\end{array}\right]$ $\in \mathbb{R}^{m \times m}$

In order to calculate the elements of the inverse matrix, some additional properties of determinants are recalled (see [12]).

Lemma 4.3. If $\mathbf{K}$ and $\mathbf{N}$ are square matrices, then $\operatorname{det}\left[\begin{array}{cc}\mathbf{K} & \boldsymbol{\Lambda} \\ \mathbf{M} & \mathbf{N}\end{array}\right]=\operatorname{det}(\mathbf{K}) \operatorname{det}\left(\mathbf{N}-\mathbf{M K}^{-1} \mathbf{\Lambda}\right) \quad$ when $\mathbf{K}^{-1}$ exists. The matrix $\mathbf{N}-\mathbf{M K}^{-1} \boldsymbol{\Lambda}$ is called the Schur complement of $\mathbf{K}$.

Lemma 4.4. If an $m \times m$ matrix $\mathbf{K}$ is nonsingular, and $\mathbf{C}$ and $\mathbf{D}$ are $m \times s$ matrices, then

$$
\operatorname{det}\left(\mathbf{K}+\mathbf{C D}^{\prime}\right)=\operatorname{det}(\mathbf{K}) \operatorname{det}\left(\mathbf{I}_{m}+\mathbf{D}^{\prime} \mathbf{K}^{-1} \mathbf{C}\right),
$$

or equivalently, if $\mathbf{c}_{i}$ and $\mathbf{d}_{i}$ are the ith columns of $\mathbf{C}$ and $\mathbf{D}$, respectively, then

$$
\operatorname{det}\left(\mathbf{K}+\sum_{k=1}^{m} \mathbf{c}_{k} \mathbf{d}_{k}^{\prime}\right)=\operatorname{det}(\mathbf{K})\left(1+\sum_{k=1}^{m} \mathbf{d}_{k}^{\prime} \mathbf{K}^{-1} \mathbf{c}_{k}\right) .
$$


TheOREM 4.5. The elements of the inverse matrix $\widetilde{\mathbf{B}} \triangleq\left(\mathbf{B}^{\prime} \mathbf{V}_{2} \mathbf{V}_{1}^{-1} \mathbf{B}\right.$ $+\mathbf{R})^{-1}$ are given by

$$
\begin{aligned}
\widetilde{\mathbf{B}}_{i i}= & \frac{1}{l_{i, 1} \cdots l_{i, d+2}} \frac{1+\sum_{i=1}^{m} \sum_{j=1}^{m} v_{j i} u_{i j} \mathbf{B}_{i} \boldsymbol{\Lambda}_{i}^{-1} \mathbf{N}_{i}^{\prime}-\sum_{j=1}^{m} v_{j i} u_{j i} \mathbf{B}_{i} \boldsymbol{\Lambda}_{i}^{-1} \mathbf{B}_{i}^{\prime}}{1+\sum_{i=1}^{m} \sum_{j=1}^{m} v_{j i} u_{i j} \mathbf{B}_{i} \boldsymbol{\Lambda}_{i}^{-1} \mathbf{B}_{i}^{\prime}} \\
\widetilde{\mathbf{B}}_{i j}= & -\frac{\sum_{k=1}^{m} u_{i k} v_{k j} \operatorname{det}\left(\mathbf{B}_{i}^{\prime} \mathbf{B}_{j}\right)}{\left(l_{i, 1} \cdots l_{i, d+2}\right)\left(j_{j, 1} \cdots l_{j, d+2}\right)} \\
& \cdot \frac{1+\sum_{r=1}^{m} \beta_{r r} \mathbf{B}_{r} \boldsymbol{\Lambda}_{r}^{-1} \mathbf{B}_{r}^{\prime}-\beta_{i i} \mathbf{B}_{i} \boldsymbol{\Lambda}_{i}^{-1} \mathbf{B}_{i}^{\prime}-\beta_{j j} \mathbf{B}_{j} \boldsymbol{\Lambda}_{j}^{-1} \mathbf{B}_{j}^{\prime}}{1+\sum_{i=1}^{m} \sum_{j=1}^{m} v_{j i} u_{i j} \mathbf{B}_{i} \boldsymbol{\Lambda}_{i}^{-1} \mathbf{B}_{i}^{\prime}} \quad \text { for } i \neq j,
\end{aligned}
$$

where

$$
\beta_{r r}=\frac{\sum_{k=1}^{m} u_{r k} v_{r k} \sum_{k=1}^{m} u_{j k} v_{k i}-\sum_{k=1}^{m} u_{r k} v_{k i} \sum_{k=1}^{m} u_{j k} v_{k r}}{\sum_{k=1}^{m} u_{j k} v_{k i}}
$$

and

$$
\operatorname{det}\left(\mathbf{B}^{\prime} \mathbf{V}_{2} \mathbf{V}_{1}^{-1} \mathbf{B}+\mathbf{R}\right)=\prod_{k=1}^{m} l_{k, 1} \cdots l_{k, d+2}\left\{1+\sum_{i=1}^{m} \sum_{j=1}^{m} v_{j i} u_{i j} \mathbf{B}_{i} \mathbf{\Lambda}_{i}^{-1} \mathbf{B}_{i}^{\prime}\right\} .
$$

Proof. This follows from Lemmas 4.1-4.3.

We also define the $m \times m$ matrix

$$
\begin{aligned}
\mathbf{M} & \triangleq\left[\mathbf{M}_{k l}\right]_{1 \leq k, l \leq m}=-\left(\mathbf{B}^{\prime} \mathbf{V}_{2} \mathbf{V}_{1}^{-1} \mathbf{B}+\mathbf{R}\right)^{-1} \mathbf{B}^{\prime} \mathbf{V}_{2} \mathbf{V}_{1}^{-1} \mathbf{A} \\
& =-\left[\begin{array}{cccc}
\sum_{t=1}^{m} \widetilde{\mathbf{B}}_{1 t} \mathbf{B}_{t}^{\prime} \sum_{k=1}^{m} \alpha_{k 1} \sum_{s=1}^{m} u_{t s} v_{s k} & \cdots & \sum_{t=1}^{m} \widetilde{\mathbf{B}}_{1 t} \mathbf{B}_{t}^{\prime} \sum_{k=1}^{m} \alpha_{k m} \sum_{s=1}^{m} u_{t s} v_{s k} \\
\vdots & \cdots & \vdots \\
\sum_{t=1}^{m} \widetilde{\mathbf{B}}_{m t} \mathbf{B}_{t}^{\prime} \sum_{k=1}^{m} \alpha_{k 1} \sum_{s=1}^{m} u_{t s} v_{s k} & \cdots & \sum_{t=1}^{m} \widetilde{\mathbf{B}}_{m t} \mathbf{B}_{t}^{\prime} \sum_{k=1}^{m} \alpha_{k m} \sum_{s=1}^{m} u_{t s} v_{s k}
\end{array}\right]
\end{aligned}
$$

and

$$
\begin{aligned}
\zeta & =\left[\sum_{t=1}^{m} \sum_{j=1}^{m} \mathbf{M}_{1 j} \alpha_{j t} \phi_{t} \cdots \sum_{t=1}^{m} \sum_{j=1}^{m} \mathbf{M}_{m j} \alpha_{j t} \phi_{t}\right]^{\prime}, \\
\mathbf{u}_{i, n} & =\sum_{j=1}^{m} \mathbf{M}_{i j}\left(x_{j, n-1}+\sum_{t=1}^{m} \alpha_{j t} \phi_{t}\right) \quad \text { for every } i=1, \ldots, m,
\end{aligned}
$$

where $\mathbf{M}_{i j} \in \mathbb{R}^{d+2}$ and

$$
\mathbf{u}_{i, n}=\left[\Delta m_{i, n}^{1} \cdots \Delta m_{i, n}^{d-1} \Delta c_{i, n} \Delta b_{i, n} \Delta \alpha_{i, n}\right]^{\prime}=\sum_{j=1}^{m} \mathbf{M}_{i j}\left(x_{j, n-1}+\sum_{t=1}^{m} \alpha_{j t} \phi_{t}\right)
$$




$$
=\mathbf{M}_{i 1}\left(\Delta P_{1, n-1}+\sum_{t=1}^{m} \alpha_{1 t} \phi_{t}\right)+\cdots+\mathbf{M}_{i m}\left(\Delta P_{m, n-1}+\sum_{t=1}^{m} \alpha_{m t} \phi_{t}\right)
$$

where $\mathbf{M}_{i j}=-\sum_{t=1}^{m} \widetilde{\mathbf{B}}_{i t} \mathbf{B}_{t}^{\prime} \alpha_{k j} \sum_{s=1}^{m} u_{t s} v_{s k}$, for $i=1, \ldots, m$.

5. A practical numerical application for the population of Greece. As a practical case study, the stochastic-discrete model for two social security pension plans and the corresponding analytic results have been applied to the social security system of Greece. We also suppose that the existing two plans cover the entire population of Greece. This is not a mere simplification, as the major part of the population of Greece is insured in the two major social security pension plans (I.K.A. and O.G.A.; in this application we assume $60 \%$ and $30 \%$, respectively).

The steps and the respective assumptions are as follows:

1. The starting date of the simulation is the year 2007 , and the closing date is the end of 2030.

2. The entry age has been fixed equal to 20 years, and the labor force participation rate equals $100 \%$.

3. The weights of $\theta_{i k}, i=1,2, k=1,2,3,4$, can take any value in the interval $[0,1]$ keeping in mind the relationship $\sum_{k=1}^{4} \theta_{i, n} \leq 1$. In our example, the weights are equal to 0.25 . In other words, the pension plan managers and the government are indifferent to the four alternatives.

4. It is assumed that the (earned annually) rate of return of different investments, such as cash $\left(r_{i, n}^{c}\right)$, bonds $\left(r_{i, n}^{b}\right)$ and shares $\left(r_{i, n}^{s}\right)$ are given by the following stationary (unconditional) autoregressive processes in discrete time of order 1 (see [5] and [8]):

$$
\begin{aligned}
r_{i, n}^{h}=\mu_{i}^{h}+\phi\left(r_{i, n-1}^{h}-\mu_{i}^{h}\right)+\xi_{i, n}^{h}, \quad \xi_{i, n}^{h} \sim N\left(0,\left(\sigma_{i}^{h}\right)^{2}\right) \\
\quad \text { for } h=c, b, s, n=1,2, \ldots
\end{aligned}
$$

This model suggests that the rate of return earned in any year depends upon rates earned in the previous year and some constant level. In [4] the following has been shown:

$$
E\left(r_{i, n}^{h}\right)=\mu_{i}^{h}, \quad \operatorname{Var}\left(r_{i, n}^{h}\right)=\frac{\left(\sigma_{i}^{h}\right)^{2}}{1-\phi^{2}}, \quad \operatorname{Cov}\left(r_{i, n}^{h}, r_{i, m}^{h}\right)=\frac{\left(\sigma_{i}^{h}\right)^{2}}{1-\phi^{2}} \phi^{|n-m|} .
$$

The condition for the processes to be stationary is that $|\phi|<1$, in our case we choose $\phi=0.6$. Moreover, we are targeting at the investment rates as in Table 3. 
Table 3. Investments return

\begin{tabular}{|c|c|c|c|}
\hline & & Mean & Deviation \\
\hline Cash & c1 & $3.50 \%$ & $0 \%$ \\
\cline { 2 - 4 } & c2 & $4.25 \%$ & $0 \%$ \\
\hline \multirow{2}{*}{ Bonds } & b1 & $4.50 \%$ & $2 \%$ \\
\cline { 2 - 4 } & b2 & $5.50 \%$ & $2 \%$ \\
\hline \multirow{2}{*}{ Shares } & s1 & $6 \%$ & $10 \%$ \\
\cline { 2 - 4 } & s2 & $8 \%$ & $10 \%$ \\
\hline
\end{tabular}

So, as $1-\varphi^{2}=0.64$, we obtain

$$
\xi_{i, n}^{b} \sim N\left(0,2.56 \cdot 10^{-4}\right), \quad \xi_{i, n}^{s} \sim N\left(0,6.4 \cdot 10^{-3}\right) .
$$

Furthermore, for the small change $\Delta r_{i, n}^{h}=r_{i, n}^{h}-r_{i, n_{0}}^{h}$, we obtain

$$
E\left(\Delta r_{i, n}^{h}\right)=E\left(r_{i, n}^{h}-r_{i, n_{0}}^{h}\right)=E\left(r_{i, n}^{h}\right)-r_{i, n_{0}}^{h}=0, \quad \operatorname{Var}\left(\Delta r_{i, n}^{h}\right)=\operatorname{Var}\left(r_{i, n}^{h}\right) .
$$

5. Each active life from the age of 20 to the age of normal retirement receives an annual salary of one monetary unit, $s_{2007}=1$, in the year 2007 and the salary increases annually according to $s_{i, n}=s_{i, n-1} f_{i, n}$ where

$$
f_{i, n} \sim N\left(\mu_{i}, \sigma^{2}\right),
$$

$\mu_{1}=1.01, \mu_{2}=1.02$ and $\sigma^{2}=5 \cdot 10^{-3}$, respectively.

Multiple regression techniques are applied to obtain estimates for the $k_{i, k}$ and $\lambda_{i, k}$, for $i=1,2, k=1, \ldots 5$. For the regression, 27 points for each of $A_{i ; n, a_{n}}$ and $P_{i ; n, a_{n}}$ have been taken by the projected values of these functions (according to Tables 3 and 4). 66\% and $44 \%$ of the entire population of Greece in the 1st and 2nd pension plan (see Tables 4, 5, and 6). By using the statistical toolbox of MATLAB, we apply a multiple full-quadratic regression model with $95 \%$ global confidence interval for the predictions.

The number of Actives is

$$
A_{i ; n, n_{a}}=\lambda_{i, 1} n+\lambda_{i, 2} a_{i, n}+\lambda_{i, 3} n^{2}+\lambda_{i, 4} a_{i, n}^{2}+\lambda_{i, 5} n a_{i, n}+\lambda_{i ; 6, n}
$$

with

$\lambda_{1,1}=1,769.46, \quad \lambda_{2,1}=911.54, \quad \lambda_{1,2}=-1,331.55, \quad \lambda_{2,2}=-887.7$,

$\lambda_{1,3}=-0.4537, \quad \lambda_{2,3}=-0.3024, \quad \lambda_{1,4}=-0.47614, \quad \lambda_{2,4}=-0.31743$,

$\lambda_{1,5}=0.73214, \quad \lambda_{2,5}=0.48881, \quad \lambda_{1,6}=-1,726.296, \quad \lambda_{2,6}=-1,150.864$.

The number of Pensioners is

$$
P_{i ; n, n_{a}}=k_{i, 1} n+k_{i, 2} a_{i, n}+k_{i, 3} n^{2}+k_{i, 4} a_{i, n}^{2}+k_{i, 5} n a_{i, n}+k_{i ; 6, n}
$$

with 
$k_{1,1}=523.46, \quad k_{2,1}=348.97, \quad k_{1,2}=838.2, \quad k_{2,2}=548.8$,

$k_{1,3}=-0.1170, \quad k_{2,3}=-0.0780, \quad k_{1,4}=1.3507, \quad k_{2,4}=0.9005$,

$k_{1,5}=-0.5496, \quad k_{2,5}=-0.3664, \quad k_{1,6}=-566,227.2, \quad k_{2,6}=-377,484.8$.

In order to incorporate a stochastic element into the functions $A_{i ; n, n_{a}}$ and $P_{i ; n, n_{a}}$, it is assumed that

$$
\lambda_{i ; 6, n} \sim N\left(\lambda_{i, 6}, \sigma_{2}^{2}=(50)^{2}\right), \quad k_{i ; 6, n} \sim N\left(k_{i, 6}, \sigma_{5}^{2}=(35)^{2}\right), \quad i=1,2,
$$

or equivalently,

$$
\Delta \lambda_{i ; 6, n} \sim N\left(0, \sigma_{4}^{2}=(50)^{2}\right), \quad \Delta k_{i ; 6, n} \sim N\left(0, \sigma_{5}^{2}=(35)^{2}\right) .
$$

Table 4. Total population of active members and pensioners in Greece, 2007-2030

\begin{tabular}{|c|c|c|c|c|c|c|}
\hline & \multicolumn{6}{|c|}{ Total population in thousands } \\
\hline & \multicolumn{7}{|c|}{ Years } \\
\hline Age bands & 2007 & 2010 & 2015 & 2020 & 2025 & 2030 \\
\hline $20-24$ & 767.9 & 630.8 & 581.7 & 549.9 & 562.9 & 585.5 \\
\hline $25-29$ & 838.7 & 770.6 & 634.2 & 585.4 & 553.7 & 566.8 \\
\hline $30-34$ & 871.4 & 860.9 & 793.9 & 658.0 & 609.4 & 577.8 \\
\hline $35-39$ & 864.4 & 872.5 & 862.3 & 795.7 & 660.4 & 611.9 \\
\hline $40-44$ & 801.8 & 876.4 & 885.1 & 875.0 & 808.8 & 674.3 \\
\hline $45-49$ & 761.3 & 787.7 & 861.9 & 870.5 & 860.7 & 795.2 \\
\hline $50-54$ & 721.3 & 777.1 & 804.1 & 877.4 & 886.0 & 876.5 \\
\hline $55-59$ & 658.9 & 695.4 & 750.7 & 777.5 & 849.9 & 858.7 \\
\hline $60-64$ & 565.6 & 648.2 & 684.7 & 739.5 & 766.7 & 838.2 \\
\hline $65-69$ & 605.4 & 531.5 & 611.1 & 647.4 & 701.3 & 728.8 \\
\hline $70-74$ & 588.5 & 568.1 & 503.2 & 579.0 & 615.4 & 668.4 \\
\hline $75-79$ & 431.6 & 501.4 & 488.2 & 435.9 & 505.0 & 541.1 \\
\hline $80-84$ & 232.2 & 312.5 & 368.4 & 362.6 & 326.8 & 383.9 \\
\hline $85+$ & 136.8 & 165.4 & 224.1 & 278.8 & 297.7 & 288.5 \\
\hline Total & $\mathbf{8 8 4 5 . 8}$ & $\mathbf{8 9 9 8 . 5}$ & $\mathbf{9 0 5 3 . 6}$ & $\mathbf{9 0 3 2 . 6}$ & $\mathbf{9 0 0 4 . 7}$ & $\mathbf{8 9 9 5 . 6}$ \\
\hline
\end{tabular}

Source: National Statistical Service of Greece (2004) [14]

Table 5. Accumulated population of active members in Greece (2007-2030)

\begin{tabular}{|c|c|c|c|c|c|c|}
\hline & \multicolumn{6}{|c|}{ Total population in thousands } \\
\hline & \multicolumn{5}{|c|}{ Years } \\
\hline & 2007 & 2010 & 2015 & 2020 & 2025 & 2030 \\
\hline $\mathbf{2 0 - 6 4}$ & 6851.3 & 6919.6 & 6858.6 & 6728.9 & 6558.5 & 6384.9 \\
\hline $\mathbf{2 0 - 6 9}$ & 7456.7 & 7451.1 & 7469.7 & 7376.3 & 7259.8 & 7113.7 \\
\hline $\mathbf{2 0 - 7 4}$ & 8045.2 & 8019.2 & 7972.9 & 7955.3 & 7875.2 & 7782.1 \\
\hline $\mathbf{2 0 - 7 9}$ & 8476.8 & 8520.6 & 8461.1 & 8391.2 & 8380.2 & 8323.2 \\
\hline $\mathbf{2 0 - 8 4}$ & 8709.0 & 8833.1 & 8829.5 & 8753.8 & 8707.0 & 8707.1 \\
\hline
\end{tabular}

Source: National Statistical Service of Greece (2004) [14] 
Table 6. Accumulated population of pensioners in Greece (2007-2030)

\begin{tabular}{|c|c|c|c|c|c|c|}
\hline & \multicolumn{6}{|c|}{ Total population in thousands } \\
\hline & \multicolumn{9}{|c|}{ Years } \\
\hline & 2007 & 2010 & 2015 & 2020 & 2025 & 2030 \\
\hline $\mathbf{6 5 +}$ & 1994.5 & 2078.9 & 2195.0 & 2303.7 & 2446.2 & 2610.7 \\
\hline $\mathbf{7 0 +}$ & 1389.1 & 1547.4 & 1583.9 & 1656.3 & 1744.9 & 1881.9 \\
\hline $\mathbf{7 5 +}$ & 800.6 & 979.3 & 1080.7 & 1077.3 & 1129.5 & 1213.5 \\
\hline $\mathbf{8 0 +}$ & 369.0 & 477.9 & 592.5 & 641.4 & 624.5 & 672.4 \\
\hline $\mathbf{8 5 +}$ & 136.8 & 165.4 & 224.1 & 278.8 & 297.7 & 288.5 \\
\hline
\end{tabular}

Source: National Statistical Service of Greece (2004) [14]

6. Moreover the interaction factors, $\beta_{i j, n}$, and $\varepsilon_{i j, n}, i, j=1,2$, are constant and equal to $\beta_{12, n}=\beta_{21, n}=0.1$ (i.e. $10 \%$ of the contingency fund is transferred from the $i$ th to the $j$ th social security pension plan, so, $\beta_{11, n}=$ $\beta_{22, n}=0.9$ ), and $\varepsilon_{11, n}=\varepsilon_{22, n}=0, \varepsilon_{12, n}=\varepsilon_{21, n}=0.05$ (i.e. there is a small transition cost).

7. The initial surplus is chosen to be 0 (monetary unit) for each subportfolio. The arrays $(50 \%, 25 \%, 25 \%, 20.653 \%, 65,80)$ and $(70 \%, 20 \%, 10 \%$, $23.603 \%, 65,70)$ (i.e. proportion invested in bonds, in shares, in cash, the contribution rate, the age of eligibility of retirement, and the benefit) are chosen as the first equilibrium point for each social security pension plan.

Table 7. Equilibrium points for the application

\begin{tabular}{|c|c|c|c|c|c|c|c|c|c|}
\hline$n$ & $\% c_{1 n_{0}}$ & $\% c_{2 n_{0}}$ & $a_{1 n_{0}}$ & $a_{2 n_{0}}$ & $b_{1 n_{0}}$ & $b_{2 n_{0}}$ & $C F_{1 n_{0}}$ & $C F_{1 n_{0}}$ & $C F_{n_{0}}$ \\
\hline 2007 & 20.6525 & 23.6029 & 65 & 65 & 70 & 80 & 0.00 & 0.00 & $\mathbf{0 , 0 0}$ \\
\hline 2010 & 20.7425 & 23.6779 & 65.1650 & 65.1200 & 69.8350 & 79.8800 & 3227,34 & 4644,36 & $\mathbf{7 8 7 1 , 7 0}$ \\
\hline 2015 & 20.8925 & 23.8029 & 65.4400 & 65.3200 & 69.5600 & 79.6800 & 6507,90 & 7338,10 & $\mathbf{1 3 8 4 6 , 0 0}$ \\
\hline 2020 & 21.0425 & 23.9279 & 65.8150 & 65.6700 & 69.1850 & 79.3300 & 7167,30 & 7450,70 & $\mathbf{1 4 6 1 8 , 0 0}$ \\
\hline 2025 & 21.1925 & 24.0529 & 66.1900 & 66.0200 & 68.8100 & 78.9800 & 5423,90 & 5049,10 & $\mathbf{1 0 4 7 3 , 0 0}$ \\
\hline 2030 & 21.3425 & 24.1779 & 66.5650 & 66.3700 & 68.4350 & 78.6300 & 614,28 & $-641,41$ & $\mathbf{- 2 7 , 1 2}$ \\
\hline
\end{tabular}

Table 8a. Simulation results

\begin{tabular}{|c|c|c|c|c|c|c|}
\hline$n$ & $\% E\left(w_{1 n}^{b}\right)$ & $\% E\left(w_{2 n}^{b}\right)$ & $\% E\left(w_{1 n}^{s}\right)$ & $\% E\left(w_{2 n}^{s}\right)$ & $\% E\left(c_{1 n}\right)$ & $\% E\left(c_{2 n}\right)$ \\
\hline 2007 & 50 & 70 & 25 & 10 & 20.6525 & 23.6029 \\
\hline 2010 & 50.032 & 70.039 & 25.065 & 20.067 & 20.7354 & 23.6739 \\
\hline 2015 & 50.110 & 70.116 & 25.219 & 20.217 & 20.8834 & 23.7912 \\
\hline 2020 & 50.105 & 70.119 & 25.209 & 20.211 & 21.0246 & 23.9180 \\
\hline 2025 & 50.132 & 70.139 & 25.263 & 20.261 & 21.1746 & 24.0362 \\
\hline 2030 & 50.004 & 70.009 & 25.008 & 20.006 & 21.3240 & 24.1731 \\
\hline
\end{tabular}

Table 8 b. Simulation results

\begin{tabular}{|c|c|c|c|c|c|c|}
\hline$E\left(a_{1 n}\right)$ & $E\left(a_{2 n}\right)$ & $E\left(b_{1 n}\right)$ & $E\left(b_{2 n}\right)$ & $E\left(C F_{1 n}\right)$ & $E\left(C F_{2 n}\right)$ & $E\left(C F_{2 n}\right)$ \\
\hline 65 & 65 & 70 & 80 & 0 & 0 & $\mathbf{0}$ \\
\hline 65.1354 & 65.1076 & 69.8357 & 79.9319 & 3183.52 & 4425.56 & $\mathbf{7 5 0 9 . 0 8}$ \\
\hline 65.3942 & 65.2913 & 69.6111 & 79.7298 & 6400.96 & 7233.11 & $\mathbf{1 3 6 3 4 . 0 6}$ \\
\hline 65.7853 & 65.6312 & 69.1982 & 79.3898 & 6824.41 & 7408.96 & $\mathbf{1 4 2 3 3 . 3 5}$ \\
\hline 66.1327 & 65.9583 & 68.8417 & 79.029 & 5233.63 & 4866.35 & $\mathbf{1 0 0 9 9 . 9 8}$ \\
\hline 66.5491 & 66.3271 & 68.4354 & 78.6797 & 588.69 & -609.78 & $\mathbf{7 8 . 9 1}$ \\
\hline
\end{tabular}


8. After the establishment of the first equilibrium point, we proceed with the design of the equilibrium path for $\bar{w}_{i, n}^{b}, \bar{w}_{i, n}^{s}, \bar{c}_{i, n}, \bar{a}_{i, n}$ and $\bar{b}_{i, n}$, $i=1,2$, for all the time periods. We use a trial and error procedure increasing annually the consecutive values of: $\bar{c}_{1, n}$ by $0.03 \%$, and $\bar{c}_{2, n}$ by $0.025 \%$ for the next time periods; $\bar{a}_{1, n}$ by 0.055 each year in $2008-2015$ and by 0.075 in $2016-2030$ and $\bar{a}_{2, n}$ by 0.04 each year in $2008-2015$ and by 0.07 in 2016-2030, and decreasing annually the consecutive values of $\bar{b}_{1, n}$ by 0.055 each year in 2008-2015 and by 0.075 in $2016-2030$, and $\bar{b}_{2, n}$ by 0.04 each year in 2008-2015 and by 0.07 in 2016-2030. Following that investment policy, we leave $m_{i, n_{0}}^{b}$ and $m_{i, n_{0}}^{s}$ stable, for $i=1,2$, targeting at a zero annual cash flow and a zero accumulated reserve $C F_{n}=C F_{1, n}+C F_{2, n}$ at the end of 2030. Finally, we calculate the actual levels for: the contingency fund, the investment rate of return due to bonds, shares, the contribution rate, the age of eligibility and the pension benefit from equations (2.2), (2.3), and (3.8)-(3.11) respectively. Then we execute 50,000 simulations and obtain the results for the expectations and standard deviations for $w_{i, n}^{b}, w_{i, n}^{s}, c_{i, n}$, $a_{i, n}, b_{i, n}, C F_{i, n}$, for $i=1,2$ and $C F_{n}$, which are presented in Tables 7,8 and Figures 1-5.

In the simulations, the optimal path for $w_{i, n}^{b}, w_{i, n}^{s}, c_{i, n}, a_{i, n}, b_{i, n}, C F_{i, n}$ for $i=1,2$ and $C F_{n}$, is quite smooth, while the resulting path for the reserve (contingency) fund exhibits oscillations, absorbing the stochastic fluctuations in mortality patterns (actually the fluctuation of $\Delta \lambda_{i ; 6, n}$ and $\Delta k_{i ; 6, n}$ ) and investment performance. This is evident from the development of the expectations and the magnitude of the standard deviations and is explained briefly below.

Note that the paths of expectations for $w_{i, n}^{b}, w_{i, n}^{s}, c_{i, n}, a_{i, n}, b_{i, n}$, and $C F_{i, n}$ for $i=1,2$ are smooth (and very close to the designed paths of the equilibrium points), and that $\operatorname{StDev}\left(w_{i, n}^{b}\right), \operatorname{StDev}\left(w_{i, n}^{s}\right), \operatorname{StDev}\left(c_{i, n}\right), \operatorname{StDev}\left(a_{i, n}\right)$ and $\operatorname{StDev}\left(b_{i, n}\right)$ are small for all the time period. The path of $E\left(C F_{i, n}\right)$ is also smooth and remains close to the path of the equilibrium points while $\operatorname{StDev}\left(C F_{i, n}\right)$ is not small (see Table 9 ), reflecting the oscillatory pattern of $C F_{n}$.

Table 9. Simulation results

\begin{tabular}{|c|c|c|}
\hline$n$ & $\operatorname{StDev}\left(C F_{1 n}\right)$ & $\operatorname{StDev}\left(C F_{2 n}\right)$ \\
\hline 2007 & 0 & 0 \\
\hline 2010 & 4304 & 4004 \\
\hline 2015 & 8533 & 9353 \\
\hline 2020 & 18454 & 21034 \\
\hline 2025 & 25566 & 29064 \\
\hline 2030 & 56654 & 50534 \\
\hline
\end{tabular}



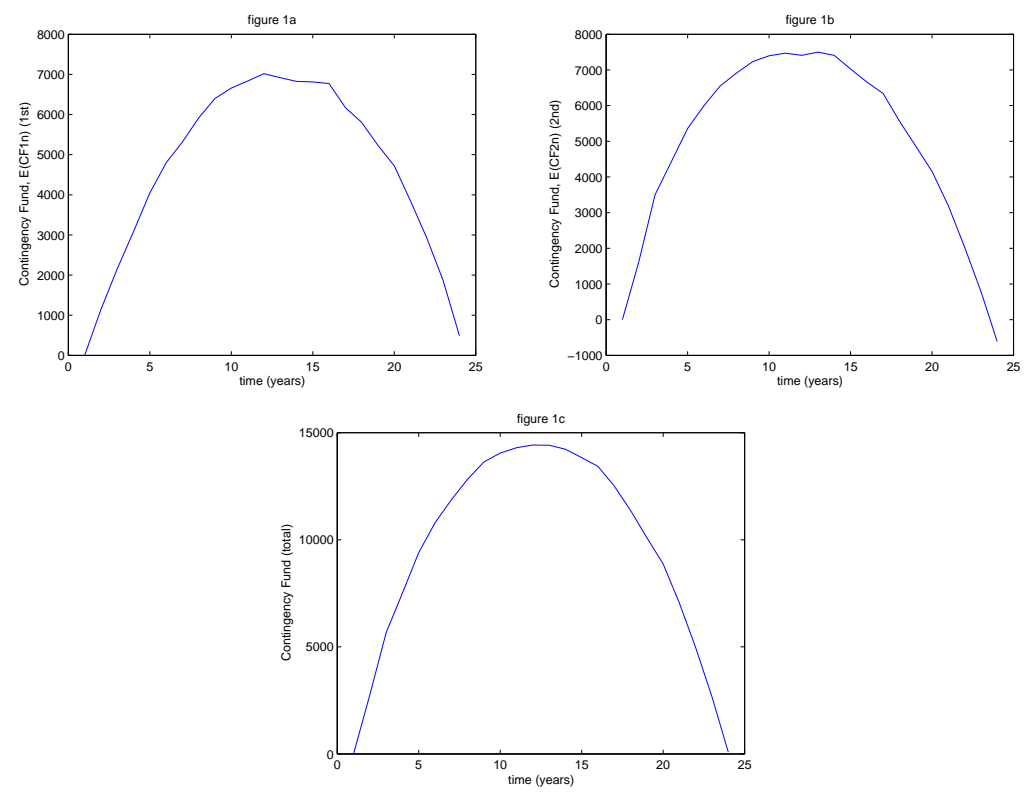

Fig. 1. The contingency fund for (a) the first, $E\left(C F_{1, n}\right)$, (b) the second, $E\left(C F_{2, n}\right)$, social security pension plan. (c) The total contingency fund for the two social security pension plans, $E\left(C F_{n}\right)$.
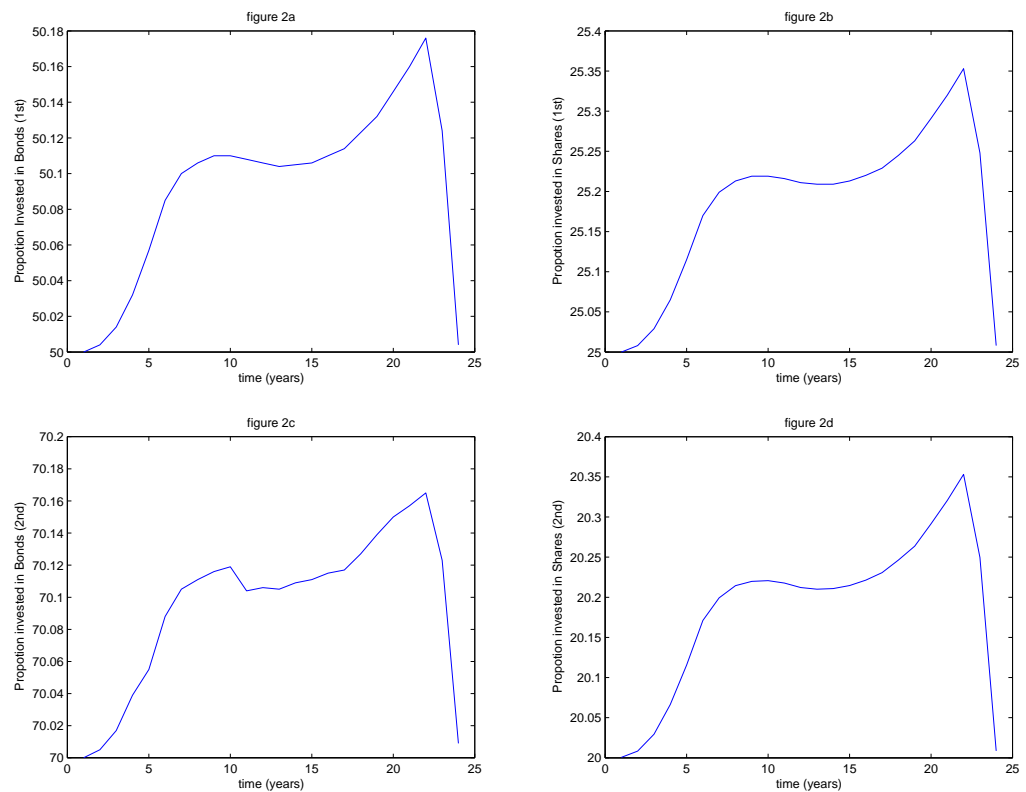

Fig. 2. Proportions invested in bonds (a) $E\left(w_{1, n}^{b}\right)$, (c) $E\left(w_{2, n}^{b}\right)$ and shares (b) $E\left(w_{1, n}^{s}\right)$, (d) $E\left(w_{2, n}^{s}\right)$ 

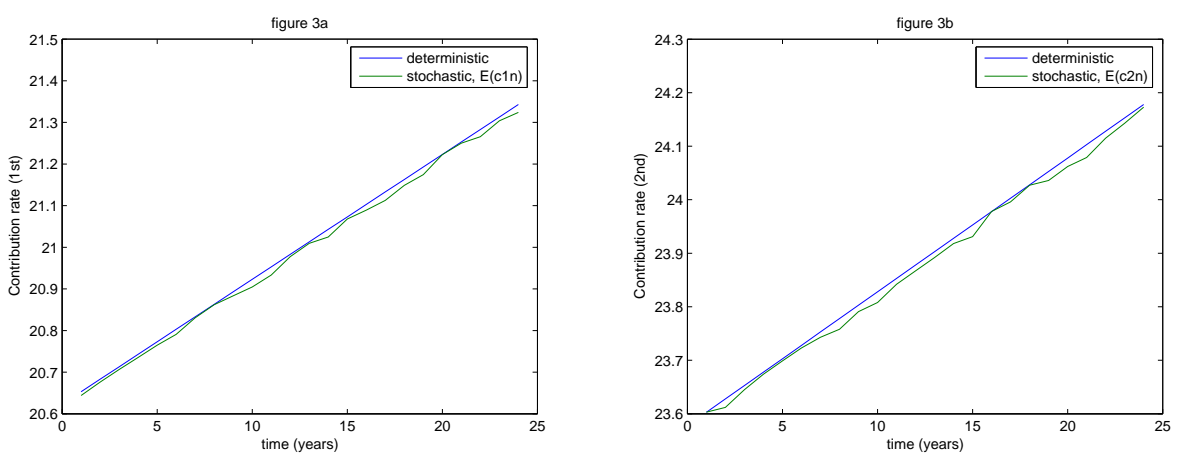

Fig. 3. Other control variables: contribution rate, (a) $E\left(c_{1, n}\right)$ and (b) $E\left(c_{2, n}\right)$, respectively
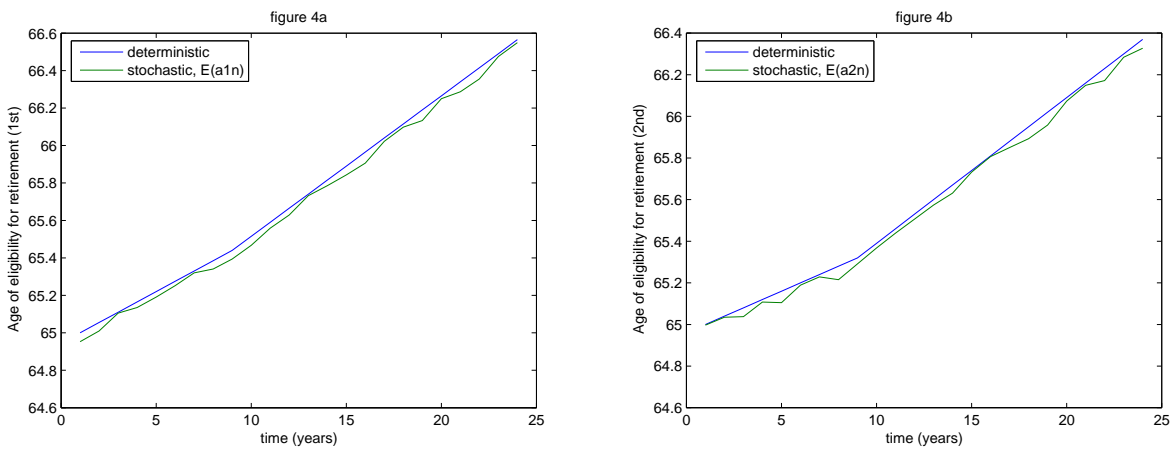

Fig. 4. Other control variables: age of eligibility for retirement, (a) $E\left(a_{1, n}\right)$ and (b) $E\left(a_{2, n}\right)$
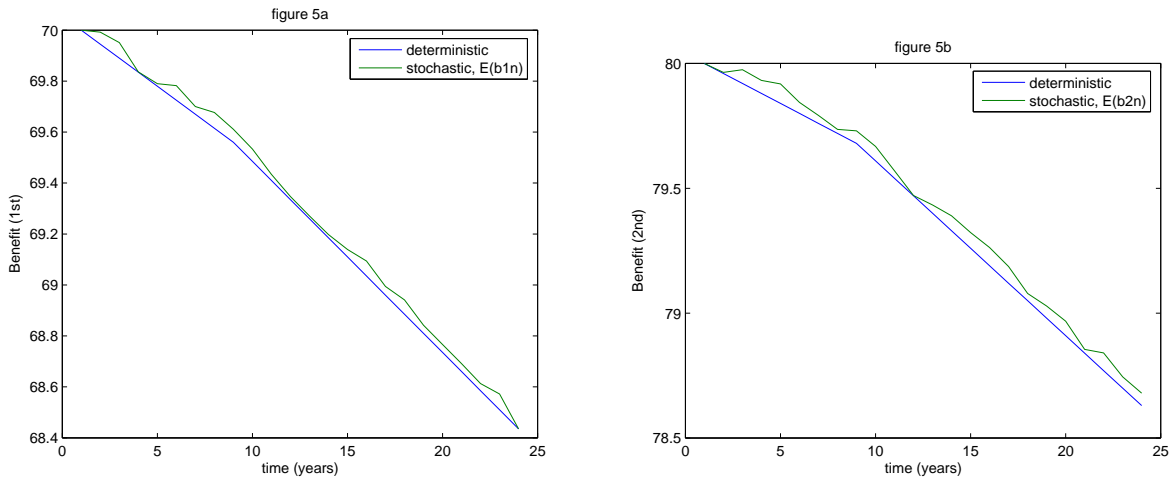

Fig. 5. The last control variables: benefits, (a) $E\left(b_{1, n}\right)$ and (b) $E\left(b_{2, n}\right)$

6. Conclusion. The paper investigates both a theoretical and a practical approach to a non-traditional, quasi PAYGO social security system by 
constructing a control discrete-time multi-dimensional model and assuming the existence of a non-zero contingency reserve fund. This fund acts as a buffer absorbing unexpectedness or other disturbances in the parameters and improving the overall performance of the system.

As regards the theoretical model, we design:

(a) $m$ state variables which correspond to the value of contingency funds of different social security pension plans.

(b) Interaction among the $m$ social security pension plans.

(c) $d+2$ control variables:

- $d$ variables that correspond to the proportions invested in different kind of investment, i.e. bonds, shares, cash, property etc.

- two variables corresponding to the contribution rate and age of eligibility for normal retirement.

(d) Input variables:

- the investment rates of returns,

- the average salary received by workers,

- modelling variables for the active members of the population and the pensioners, and

- the percentage of contingency fund transferred from the $i$ th social security pension plan to the $j$ th plan and the corresponding cost.

(e) A functional which corresponds to the objective function of the problem. In our model the functional contains seven smoothing variables (the same as the controls).

As regards the practical application, we model:

(a) the rates of the investment returns assuming stationary (unconditional) autoregressive processes in discrete time of order 1 ,

(b) the fluctuations in the salaries and mortality patterns by assuming that the fluctuations in the total number of active workers or pensioners are described via normal distributions.

The numerical application to the projected population of the Greece for the years 2007-2030 provides results compatible with the theoretical analysis. These results show (see Figures 1-5) a steadily increasing pattern for the investment mix (towards riskier solutions in order to enlarge the potential investment procedures), the contribution rate and age of eligibility for normal retirement while a decreasing pattern for the level of pension and disability benefits. The total increase of the contribution rate and the age of eligibility for normal retirement is less than anticipated by [9]. That is expected as in our model there are additional smoothing variables, the investment mix, the level of the pension and the disability benefit which ab- 
sorb a certain percentage of the incurred cost attributable to the decreasing trend of the support ratio during the years up to 2030.

Acknowledgements. The authors are grateful to the anonymous referee and the editors for their insightful comments, which improved the quality of the paper.

This work was supported by the reinforcement program of Human Research Manpower "PENED" in the framework of Measure 8.3, Action 8.3.1 of the Operational program of competitiveness; Third Community Support Program.

\section{References}

[1] B. D. O. Anderson and J. B. Moore, Optimal Control. Linear Quadratic Methods, Prentice-Hall, Englewood Cliffs, 1990.

[2] P. J. Antsaklis and A. N. Michel, Linear Systems, McGraw-Hill, 1997.

[3] D. P. Bertsekas, Dynamic Programming and Control Theory, Athens Sci., 2000.

[4] G. E. P. Box and G. M. Jenkins, Time Series Analysis, 2nd ed., Holden-Day, San Francisco, 1976.

[5] P. J. Brockwell and R. A. Davis, Introduction to Time Series and Forecasting, 2nd ed., Springer, New York, 2002.

[6] Guanrong Chen, Goong Chen and S.-H. Hsu, Linear Stochastic Control Systems, CRC Press, 1995.

[7] W. Enders and H. Lapan, Social security taxation and intergenerational risk sharing, Int. Economic Rev. 23 (1982), 647-658.

[8] S. Haberman, Autoregressive rates of return and the variability of pension contributions and fund levels for a defined benefit pension scheme, Insurance Math. Economics 14 (1994), 219-240.

[9] S. Haberman and A. Zimbidis, An investigation of the Pay-As-You-Go financing method using a contingency fund and optimal control techniques, North Amer. Actuarial J. 6 (2002), 60-75.

[10] D. Kressner, Numerical methods and software for general and structured eigenvalue problems, $\mathrm{PhD}$ dissertation, Univ. of Berlin, 2004.

[11] H. J. Kushner, An Introduction to Stochastic Control Theory, Wiley, New York, 1970 .

[12] C. D. Meyer, Matrix Analysis and Applied Linear Algebra, SIAM, Philadelphia, 2000 .

[13] B. C. Moore, On the flexibility offered by state feedback in multivariable systems beyond closed loop eigenvalue assignment, IEEE Trans. Automatic Control 21 (1976), 689-692.

[14] National Statistics Service of Greece, Statistical data for the development of the Greek population in 2005-2030, in: Population Report Series, 2004; http://www. statistics.gr or http://www.statistics.gr/gr_tables/S201_SPO_5_TS_05_30_10_Y.htm.

[15] W. J. Runggaldier, Concepts and methods for discrete and continuous time control under uncertainty, Insurance Math. Economics 22 (1998), 25-39.

[16] V. Sima, Algorithms for Linear-Quadratic Optimization, Pure Appl. Math. 200, Dekker, New York, 1996. 
[17] H. W. Sinn, Pension reform and demographic crisis. Why a funded system is needed and why it is not needed, Int. Tax Public Finance 7 (2000), 389-410.

[18] A. Smith, Intergenerational transfers as social insurance, J. Public Economics 35 (1982), 75-96.

[19] Ø. Thøgersen, Reforming social security: assessing the effects of alternative funding strategies, Appl. Economics 33 (2001), 1531-1540.

[20] A. D. Wilkie, Mutuality and solidarity: Assessing risks and sharing losses, British Actuarial J. 3 (1997), 985-986.

[21] W. A. Wolovich, Automatic Control Systems: Basic Analysis and Design, Saunders College Publ., 1994.

Department of Statistics

Athens University of Economics and Business

76 Patision St.

Athens GR-104 34, Greece

E-mail: apantel@aueb.gr

Received on 22.2.2007;

revised version on 28.4.2008 